\title{
Innovative products and services for sustainable societal development: Current reality, future potential and challenges
}

J ussi Kantola, Yang Liu, Pekka Peura, Tim de Leeuw, Yingfeng Zhang, Marja Naaranoja, Aviv Segev and Donald Huisingh

The self-archived postprint version of this journal article is available at Linköping University Institutional Repository (DiVA):

http:/ / urn.kb.se/ resolve?urn=urn:nbn:se:liu:diva-150320

N.B.: When citing this work, cite the original publication.

Kantola, J., Liu, Y., Peura, P., de Leeuw, T., Zhang, Y., Naaranoja, M., Segev, A., Huisingh, D., (2017), Innovative products and services for sustainable societal development: Current reality, future potential and challenges, J ournal of Cleaner Production, 162, S1-S10.

https:// doi.org/ 10.1016/j.jclepro.2017.07.091

Original publication available at:

https:// doi.org/ 10.1016/j.jclepro.2017.07.091

Copyright: Elsevier

http:// www.elsevier.com/

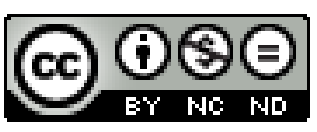




\title{
Innovative products and services for sustainable societal development: Current reality, future potential and challenges
}

Jussi Kantola ${ }^{1 *}$, Yang Liu ${ }^{1,2 *}$, Pekka Peura ${ }^{3}$, Tim de Leeuw ${ }^{4}$, Yingfeng Zhang ${ }^{5}$, Marja Naaranoja ${ }^{1}$, Aviv Segev $^{6}$, Donald Huisingh ${ }^{7}$

1) Department of Production, University of Vaasa, Finland

2) Department of Management and Engineering, Linköping University, Sweden

3) Levón Institute, University of Vaasa, Finland

4) TIAS School for Business and Society, Tilburg University, the Netherlands

5) School of Mechanical Engineering, Northwestern Polytechnical University, China

6) Graduate School of Knowledge Service Engineering, KAIST, South Korea

7) Institute for a Secure and Sustainable Environment, University of Tennessee, Knoxville, TN, USA

* Corresponding authors: jussi.kantola@uva.fi (J. Kantola), yang.liu@liu.se (Y. Liu)

Highlights (max 85 characters including space)

- Editorial to the special volume

- Goals of innovative products and services for sustainable societal development

- Introduction of the themes and papers under each theme in this special volume

\begin{abstract}
This special volume originates from the International Conference on Innovation and Management held at University of Vaasa in Finland in 2014. Talks with the key note speaker and Editor-inChief of the Journal of Cleaner Production led to an idea to develop a special volume about innovative products and services according to the themes of the conference. Thus, the purpose of this special volume is to explore different viewpoints of how innovative products and services may support sustainable societal development. There are five thematic areas with papers that describe new advancements in different industries and organizations. The included papers cover relevant theoretical background and present case studies and practical results. This special volume shows that great progresses are being made in different thematic areas but also that there are so much more waiting to be done for sustainable societal development. This volume indicates that crossdisciplinary approach is truly needed to achieve societal sustainable development. This requires people to change their mindsets and genuinely co-operate towards better future.
\end{abstract}

\section{Keywords}

Editorial; Innovative products and services; Innovation; Sustainable development; Sustainable societal development 


\section{Introduction}

Sustainable development is a broad field that needs innovation. The challenges facing societies in seeking to make sustainable development a reality are complex and no single innovation will be sufficient for societies to make the necessary transitions to equitable, sustainable, liveable postfossil carbon societies. Societies require a wide diversity of innovations make real progress. Therefore, multi-disciplinary thinking, co-operation, research and practice are needed. The best way to 'solve' the complex challenges presented by climate changes and numerous other problems is to search for, test, adapt and ensure widespread implementation of truly effective, innovative solutions in a multi-disciplinary manner. It is essential to break away from the old, stagnant ways of thinking to create sustainable and equitable solutions. The objectives of this special volume (SV) of the Journal of Cleaner Production (JCLP) were based on this common-sense reasoning. The SV has the following themes: 1) Sustainable Energy Innovations, Green Products and Services; 2) Open Innovation and Collaboration for Sustainable Social Development; 3) Sustainable Operations and Supply Chain Management; 4) Remanufacturing and Networked Manufacturing; and 5) Knowledge Management for Sustainable Societal Development. Theme 1 Sustainable Energy Innovations, Green Products and Services was clearly the most popular theme in the SV with most submissions and papers in the SV. In the following sections the objectives of the SV and the content of the articles in the five themes are reviewed.

The first objective of the SV was to explore new innovations and their management in several thematic areas, which in different ways can contribute to sustainable societal development. The second objective of the SV was to explore holistic and innovative ways to combine advancements in different fields, and to develop overarching sustainable solutions. To meet these objectives, several thematic areas were addressed. The themes cover products and services as well as their production, operations, and supply chains. Parallel to these themes, Innovation management, Knowledge management and Information and Service technology were presented and reviewed. These themes cover tangible and intangible elements that are needed to develop, test and implement sustainable solutions. These themes are introduced and the findings presented in the articles are highlighted and contextualized.

\section{Themes in this special volume}

\subsection{Sustainable energy innovations, green products and services}

Guest editor: Peura, Pekka

Sustainable energy (SE) has become one of the key approaches for reforming the energy sector in the EU and worldwide to accelerate the transition to equitable, sustainable, post-fossil carbon societies. As the production of energy has caused and is causing major impacts on the environment, "Renewable energy is one of the most efficient ways to achieve sustainable development" 
(Goldemberg, 2007), and "One of the main tasks in this century (...) will be to manage a transition process to sustainable energy systems" (Haas et al., 2008). The concept of SE was recently reviewed, and redefined by (Peura, 2013) as follows: rational use of energy (RUE); energy efficiency and energy saving; renewable energy sources (RES); materials and other sources (biomass, wood, hydro, solar, geo, wind, wave, tidal, ocean thermal energy conversion (OTEC) ..., etc.), Integration of RUE and RES, as well as Sustainability Management.

There are many technologies for both RUE and for producing and utilising RES. They can be implemented as separate solutions or be designed and used in integrated systems. The integration of RUE and RES technologies and management will be the key to planning and implementing complete solutions. With different combinations of the RUE and RES technologies and regional RES energy, it will be possible to develop, implement, monitor and manage 'solutions' with different degrees of energy self-sufficiency. This concept can be applied to any target building, company, community, region, or nation or groups of nations. It is essential to establish governmental and corporate policies and management systems for avoiding a new field of ecological colonialism in the name of SE. The novelties in this field will arise from integrating separate technologies into system-wide level innovations including green products and services.

\subsubsection{In this theme}

There are five articles in this theme: "Study of institutional change in transportation," by de Leeuw and Gössling, in Volume 135, Pages 435-448; "Analysis of manufacturers' portfolio decisions on the electric car market diffusion," by Kieckhaefer, Wachter and Spengler, in this issue; "Research of the failures in bilateral energy exchange projects," by Phuc and Matsuura, in this issue; "Analyses of the adoption of sustainable energy systems into corporate financial performance," by Marti, in this issue; and "Exploration of the role of users in the green innovation processes of incumbent firms," by Purtik, Zimmerling and Welpe, in this issue.

De Leeuw and Gössling reviewed case studies, including Uber, to gain insights from early adopters for institutional environmental change in transportation in taxi operations. They validated and extended the process model for institutional change by Greenwood et al. (2002). Their proposed new model describes different phases of institutional change.

Kieckhaefer, Wachter and Spengler applied the automotive market simulator (AMaSi) to analyse the leverage of manufacturers to support the market diffusion of electric vehicles. The model was parameterized for the German car market to simulate different product portfolio options. The authors documented that manufacturers' portfolio decisions influence the market development of electric vehicles.

Phuc and Matsuura made research on the reasons behind the failure of coordination in bilateral energy exchange projects. They aimed at designing a sustainability framework for coordination of such bilateral energy exchange projects and to increase their feasibility. The authors proposed potential solutions and guidelines for bilateral energy exchanges. 
The article by Marti analysed whether the adoption of sustainable energy systems improves corporate financial performance. The dataset covered hundreds of multinational companies from 36 countries in the timeframe of 2008-2013. The results showed that the adoption of sustainable energy systems was beneficial for short-term corporate financial performance, and had no effect in the long-term.

Purtik et al. studied the role of users in the green innovation processes of incumbent firms. They made a comparative case study of e-mobility and smart housing by using three European incumbent firms to integrate users at different stages of the innovation process. Their results showed that firms may profit from an extensive user input throughout all phases of the innovation process to develop novel green products and services.

\subsubsection{Current reality}

The whole energy sector is experiencing many changes, a transition away from fossil-carbon fuelled towards RES systems globally. It is clear, that this process is primarily much more than merely technical changes, it is a comprehensive societal change process, where all societal and ecological spheres are or must be involved, including economy and regional economy, legislation, environmental matters, societal acceptance, policies and agreements etc. Also, it involves or must involve all stakeholders from energy utilities and manufacturers to institutions, municipalities, politicians, enterprises, farms and separate consumers and individual clients. Moreover, the roles are shifting for instance from merely being a customer to participating in decision-making and becoming an individual or collective producer of renewably-based energy.

In this transition, the theoretical and actual, real-world constellations are complicated. As in any innovation diffusion process, there are many perspectives and aspects that must be integrated in research and aligned in practical development. Business in this field is not "business-as-usual", as there are many societal, global aspirations, actions, agreements and policies in the background, all having their impacts on the operational environment in the evolving sector. However, all technical innovations, societal concepts and investments must be installed in real time markets, where today the established prevailing systems are very strong and competitive.

\subsubsection{Future potential and challenges}

Future potential and challenges in this transition are highly obvious: Changes are taking place globally, in an accelerating pace, and continuously new emerging concepts and innovations are being developed, tested, adapted and implemented. The potential is enormous, purely technically and economically this will be one of the most profitable field of business in the coming 10-20 years. The vast challenges and potentials will, be the abatement of climate change, as the production of energy has traditionally been the main source of emissions. Recently, the significance of regional economies, the so called regional value added, has emerged on the arena: the huge money flows away from regions for buying fossil-carbon-based energy can, in the future be kept "at home", circulating within or near to each region - and thus stimulating the regional 
economies and rural vitality. Rural areas might even attain a new societal role, besides the former primary production roles that they played, for instance, they may become leaders in the production of energy and sources of energy for the whole society.

But the transition will not be easy. The prevailing structures are strong and will not voluntarily give away their market shares. Fossil fuel industries and value chains still enjoy nearly 10-fold subsidies compared with RES support, despite global agreements and national policies. In this institutionally subsidised market, it will be challenging to find feasible solutions unless these subsidies are removed and in addition that they be responsible for paying fossil-carbon surcharges. That will help to change the equation dramatically and quickly. That is already happening in many countries.

All technical, policy, educational, ethical innovations must be implemented in this complex world of changing societal structuration, where the operational environment is all but stable. There is a strong societal will, but operations in real time business will be demanding - without reasonable policy, attitudinal, ethical, societal changes and pressures to look at the longer-term consequences of 'business-as-usual,' the essential transitions will be too slow to avoid dramatic and devastating climate changes.

Considering this background, it is not surprising that innovations are necessary in all levels of RES systems, including:

- Single separate technical solutions;

- Systemic innovations and solutions, solving regional challenges and integrating multiple solutions to meet present and anticipated demands and needs;

- Societal innovations, including different forms of entrepreneurship, participation in regional decision-making and changing national policies

- Expanded educational initiatives from the kindergarten to life-long learning to help society to become informed and empowered to become actively engaged in being parts of the solution, rather than continuing to only being parts of the PROBLEM!

This section of this SV presents and reviews some of these kinds of innovations that have emerged for breaking this "evil circle" of the systemic difficulty of developing and implementing the great idea of Sustainable, Renewable Energy Systems on a broad-scale in an increasingly rapid pace, globally.

\subsection{Open innovation and collaboration for sustainable societal development}

Guest editor: de Leeuw, Tim 
Sustainable development has become, and increasingly is, one of the strategic focal points of organizations (Kantola et al., 2015). To achieve sustainable development, organizations can innovate their products, processes and services. These innovations are decreasingly accomplished solely due to their internal research and development activities; they are increasingly looking outside their boundaries to other actors with whom they can collaborate. There are several factors that have diminished organizations' general ability to "go at it alone," including the increasing complexity of products and processes, the rising costs of research and development, environmental dynamism, the dispersion of resources and knowledge, and the growing importance of time-tomarket. These factors have resulted in an inability of individual organizations to obtain all the elements they need (like resources) through their own efforts, and consequently, they are turning to others to obtain the necessary additional elements (Levine and White, 1961). This has resulted in a tendency for organizations to collaborate.

These collaborations are defined as the "relatively enduring transactions, flows, and linkages that occur among or between an organization and one or more [other] organizations [or other actors like individuals] in its environment" (Oliver, 1990; p. 241). These collaborations between/among actors are playing or will play important roles in the current and future organizational landscapes. In the past decade, scholars have recognized this and developed concepts and frameworks to study these types of collaborations. One of the most prominent framework is open innovation (Chesbrough, 2003), which focuses on collaborations between/among actors for fostering innovation. Under this framework, organizations collaborate with others to complement and supplement their internal innovation efforts (Deeds and Rothaermel, 2003; Poot, Faems, and Vanhaverbeke, 2009).

Due to these factors and the development of frameworks such as open innovation has spurred academic research on organizational collaborations (e.g., Inter-Organizational Relations) and numerous academic studies have shown that these collaborations in the form of alliances or mergers and acquisitions have become widespread in the last few decades (e.g., De Man and Duysters, 2005). In other words, organizational collaborations are an everyday phenomenon that has attracted great academic research interest and continues to do so. Research has shown that these organizational collaborations have numerous advantages, including knowledge transfer (Mowery, Oxley, and Silverman, 1996) and supply chain integration (Metters, 1997), which leads to better organizational performance (Rosenzweig, Roth, and Dean, 2003), input quality improvements, process innovation, cost reductions (Hagedoorn, 1993), product and service improvements, new product ideas (Von Hippel, 2007), the development of new products (Belderbos, Carree, and Lokshin, 2004), market expansion (Tether, 2002), Corporate Social Responsibility (McDonald and Young), and the ability to deal with uncertainty (Beckman, Haunschild, and Phillips, 2004).

However, negative effects of these organizational collaborations have also been found, such as the dependency created between/among collaborating organizations (Singh and Mitchell, 1996), competition (Park and Russo, 1996), conflict, unintended spillovers (of knowledge or other 
resources), and risks (Das and Teng, 1996). These negative effects point to a need for investigating and new ways of managing the collaborative dimensions of organizations

\subsubsection{In this theme}

There are three papers in this theme. The quantitative paper by Mothe and Nguyen-Thi in this issue incorporated the temporality (i.e., persistently or sporadically) of open search, from a multidimensional perspective, on French firm's environmental innovations. Their results show that the temporal dimension of openness matters. Additionally, the different dimensions of open search have diverse effects on different types of environmental innovations.

The paper by Hyysalo Johnson and Juntunen in this issue employed both qualitative and quantitative methods to focus on the diffusion of user innovations in cleaner technologies in Finland. Their findings revealed that collaboration with consumers can aid the diffusion though commercial channels and accelerate peer diffusion. However, prosumers' efforts to diffuse their solutions remain at a relatively low level, which indicates the added value of platform developments to help to support and accelerate wide-spread diffusion and implementation of new concepts and products, or product-service combinations.

The paper by Matinheikki, Rajala and Peltokorpi in this issue investigated qualitatively a publicprivate-partnership and focused on how institutional changes for sustainability can be achieved in a collective manner. The findings showed that achieving a shared value paradigm is complicated by the actors' relationships with their environments (socio-material, organizational and institutional). The authors developed a theoretical framework delineating shared value creation through three active phases: (1) shaping the vision by forging the norms in the institutional realm, (2) sharing the vision through collaborative actions in the organizational realm, and (3) anchoring the vision by casting the foundations in the socio-material realm.

\subsubsection{Current reality}

Existing research on organizational collaborations can be categorized into four levels of analysis: the dyadic level, the triad/group level, the whole network level, and the portfolio level. The dyadic level mainly pertains to two collaborating organizations and their relationships. This line of research has focused, for instance, on aspects of the relationships between/among the organizations (i.e., the tie) or of the partnering actor (i.e., the partner), sometimes in relation to the focal organization (e.g., topics like trust and control, Das and Teng, 1998). The triad/group level incorporates the relationships (or lack hereof) among three or more organizations and focuses primarily on structural elements, such as brokerage network positions (e.g., Ahuja, 2000; Burt, 2005). The whole network level incorporates all organizations and their inter-relationships in a network setting, such as a specific industry. Research on the whole network level has amongst others investigated the development and management of these networks (see Provan, Fish, and Sydow, 2007). 
As opposed to the research at the whole network level, where an organization has limited influence on its partners' partners, the portfolio level recognizes that organizations can influence and manage their own portfolios of collaborations. Investigating the portfolio level is therefore, especially valuable from a managerial perspective. Furthermore, and in contrast to research on the dyadic and triad/group levels, analysis of the portfolio level (also called the egocentric level) incorporates all of the collaborations of a focal organization which has two advantages. First, the portfolio level enables scholars and practitioners to simultaneously incorporate multiple collaborations at one point in time (Wassmer, 2010). Literature shows that organizations frequently maintain multiple collaborations, such as alliances, at any given point in time. A study by De Man, Duysters, Krijnen, and Luvison (2011) across multiple sectors for instance indicated that over $60 \%$ of the organizations maintained fifteen or more alliances at once and over $20 \%$ had more than forty alliances simultaneously.

Second, the portfolio level incorporates possible synergistic and antagonistic effects into the focal organization's collaborations (Wassmer and Dussauge, 2011). An example of a possible synergistic effect would be simultaneous collaborations with: a research institute to develop a new product; a supplier to dovetail the new sustainable production process for that product with the new supplies that will be needed; and a customer in a specific market to reduce uncertainty about the product launch. An example of an antagonistic effect would be two separate collaborations with partners who are each working on a competing sustainable new technology, only one of which will become the dominant or usable design in the market, meaning that only that collaboration has potential long-term added sustainable value. Recent literature (e.g., Wassmer and Dussauge, 2012; Belderbos, Carree, and Lokshin, 2006) documented that synergies between collaborations such as alliances do indeed have positive effects on the value derived from portfolio-level collaborations.

\subsubsection{Future potential and challenges}

Research on this relatively new level of analysis (i.e., the portfolio level) has developed from investigating the positive impacts of the number of collaborations (e.g., Keil et al., 2008) on, for instance, innovation and has started to focus on aspects such as the diversity in the collaborations portfolios (Wassmer, 2010). There are several dimensions at the portfolio level in which the diversity aspect can be investigated. First, the diversity aspect allows for the investigation of the different modes of collaborations (e.g., alliances, corporate venture investments, joint ventures, and mergers and acquisitions) and the possible synergistic and antagonistic effects among these modes. Recent work (e.g., Sabidussi et al., 2014) has shown that organizations maintain multiple collaboration modes at one point in time and that synergetic effects between/among these modes (i.e., alliances and merges/acquisitions) can yield significant benefits. As such, integrating different collaborative modes can be more effective than specializing in a single mode.

A second aspect that can be investigated is the diversity of the different types of partners (e.g., buyers, suppliers, research institutes, etc.) in the collaboration portfolio and the possible synergistic and antagonistic effects between them. Recent studies in this area have focused on the 
relationships between the diversity of partners within one mode of collaboration (i.e., alliances) and multiple performance dimensions. Results reveal both positive (e.g., Srivastava and Gnyawali, 2011) and inverted U-shaped effects (e.g., De Leeuw et al., 2014). The later indicates that the performance effects of adding an additional partner type to the portfolio of collaborations might be dependent of the existing level of diversity. This means that the diversity of the collaboration portfolio changes over time and as such a dynamic perspective might be beneficial to uncover how organizations change their diversity, depending on the external factors and on their impacts upon performance in the short and long-term future of the company or companies involved.

Although, previous studies have enriched our understanding on the performance effects of different dimensions of the collaboration portfolio, they frequently focused on innovative performance as the dependent variable. Thus, limited research has been conducted specifically on the impact of these collaborations at the portfolio level on sustainability. Additionally, studies investigating the antecedents and dynamics of these diverse aspects in the collaboration portfolio are scant, although a better understanding of factors that influence the composition of the collaboration portfolio can aid managers in improving their collaborative processes and performance. Overall the research area of collaborations at the portfolio level remains an interesting area for much future exploration.

\subsection{Sustainable operations and supply chain management}

Guest editors: Liu, Yang and Zhang, Yingfeng

During recent decades, growing societal and governmental pressures have challenged businesses to focus on the environmental and resource consequences of their production processes and of their products and services (Kleindorfer et al., 2009). More attention is needed for them to optimize their supply chains, from product design, raw materials selection, processing of the raw materials into products, to delivery, service of those products for the customer and managing them at the end-of-product-life phase (Linton et al., 2007). To succeed within the context of global competition and to fulfil sustainable development requirements, both operations and resources must be optimized for achieving sustainable competitive advantage (Liu, 2013; Liu and Liang, 2015), and sustainable supply chain management must integrate optimization strategies and methods to focus on social, economic and environmental concerns (Govindan et al., 2014).

\subsubsection{In this theme}

There are two papers in this theme. The authors of one paper Sun et al. addressed sustainable operations in terms of environmental impact based on product-service system (PSS) and the authors of the other paper Bendul et al. investigated social aspects of sustainable supply chains. 
The paper by Sun, Liu, Sakao and Wang in this issue investigated an aero-engine overhaul service as a typical sustainable PSS. They divided the PSS into multiple sub-services and created a hierarchical service tree model. They investigated the costs and energy consumption to fly various flights with diverse thrust requirements. To test this approach, a case study was performed.

The paper by Bendul, Rosca, and Pivovarova in this issue addressed sustainable supply chain management for 'Base-of-the-Pyramid' markets with the requirement of the incorporation of social aspects. The authors linked the sustainable supply chain management discourse with insights from 'Base-of-the-Pyramid' studies to develop an integrated sustainability perspective. To accomplish this objective, they used a multiple case study design based on secondary data analysis to investigate supply chain concepts of eighteen successful products, and developed sustainable supply chain models in the areas of sourcing, making and delivering. They found that by employing localized and simplified approaches, companies targeting low-income markets could overcome existing local institutional barriers. In addition, by employing simplified and localized approaches to supply chains and simultaneously integrating local communities in the value creation activities could serve as success factors. Therefore, by linking sustainable supply chain with the 'Base-of-the-Pyramid' strategies discourse, the derived supply chain models served as best practices for managers of multi-national companies, local entrepreneurs, non-governmental organizations and political institutions designing, operating and regulating supply chains for lowincome markets.

\subsubsection{Current reality}

Operations management $(\mathrm{OM})$ approaches can provide a vital sustainability perspective. Operation decision-making of the enterprise determines the production and distribution technologies that they employ. These, in turn, influence the efficiency of materials and energy usage as well as the intensity of waste released into the eco-system, which when aggregated, helped the researchers to determine the sustainability of an ecosystem (Drake and Spinler, 2013). Sustainable OM, therefore, has the potential to contribute to solutions for the sustainability challenges that we currently facing. To fulfil that potential, we must perform more research in product design, technology choices, and supply chain management (SCM) (Beske et al., 2008; Islegen and Reichelstein, 2011; Plambeck and Wang, 2009), which enables production and distribution systems to operate more efficiently as well as socially and ecologically more sustainable in the short and long-term future.

In the perspective of product design, Plambeck and Wang (2009) analysed the impacts of e-waste collection alternatives on new product development. They found that 'fee-upon-sale' schemes enhance sustainability by inducing manufacturers to introduce new products less frequently but with higher quality. Agrawal and Ülkü (2013) integrated product design, engineering, and OM perspectives into specific product categories, which helped them to connect their findings to managerial policies and practices. Raz et al. (2013) studied firm investments to improve environmental performance in the manufacturing and use stages of a product's life cycle. They 
showed that firms should invest more in improving the environmental efficiency of manufacturing for functional and innovative products.

In the perspective of production technology choices, the adoption of cleaner technologies was found to be a necessary condition for sustainability. Islegen and Reichelstein (2011) recommended carbon policy by estimating the break-even emissions prices for the adoption of carbon capture and storage technologies in power generation. Drake et al. (2015) analysed a firm's optimal

portfolio of discrete technologies under carbon regulations; they advised on carbon policies by countering the conventional wisdom. The result showed that the firm earned more profits under a cap-and-trade system than under a carbon tax regime.

In the perspective of SCM, sustainable SCM was defined as the management of materials, information and capital flows, and cooperation between/among companies along the supply chain, while, considering goals from all three dimensions of sustainable development (Seuring and Muller, 2008). Van Hoof and Thiell (2014) tested a model of collaboration capacity for sustainable SCM. The operational and cooperative routines of firms to design and to implement the results of cleaner production were measured. Wu et al. (2015) proposed using big data analytics to explore the attributes of risks and uncertainties of sustainable SCM. Based on these attributes, the big data of supply chain can be transformed to a manageable scale to consider their impacts on sustainable SCM.

\subsubsection{Future potential and challenges}

Owing to the pressures from customers and governments on firms to strive for sustainability, it has become a challenging task in SCM (Andersen and Skjoett-Larsen, 2009; Wolf, 2011). Following the concept of sustainability, firms increasingly endeavour to integrate the economic, environmental, and social aspects of sustainability to achieve the triple bottom line (Govindan et al., 2013). It is obvious that there is an urgent need for research on advanced theories and techniques to address the above-mentioned issues of sustainable SCM.

Regarding economic sustainability, Smith and Tranfield (2005) documented that current studies focus on OM's positive impacts on operating results throughout the entire supply chain, but there were no studies on the financial results of companies that are part of a sustainable SCM. Wee and $\mathrm{Wu}$ (2009) underscored the importance of Lean principles in sustainable SCM. Nevertheless, it was recognized that these principles only extend to first-tier manufacturers and suppliers in the supply chain, which makes it difficult to achieve sustainable results throughout the entire supply chain. Comm and Mathaisel (2008) highlighted that the logistics and distribution systems should be improved, and the cooperative relationships with customers and suppliers should be continuously improved.

Regarding environmental sustainability, a growing interest has arisen in addressing the complementarity of strategies or possible conflicts between sustainable SCM and environmental sustainability (Mollenkopf et al., 2010). The sustainable SCM can facilitate the adoption and 
spread of environmental innovations among stakeholders during the lifecycle, and thus improve environmental performance along the entire supply chain (Corbett and Klassen, 2006; MartínezJurado and Moyano-Fuentes, 2014). Therefore, identifying potential conflicts between sustainable and green supply chains, and developing solutions to build upon the positive effects and to mitigate their negative effects can help the sustainable SCM to be more efficient and effective and thus to become more sustainable (Carvalho et al., 2011; Dües et al., 2013; Mollenkopf et al., 2010).

Regarding social sustainability, the impact of existing OM and SCM systems on issues related to health and safety in the work place has received the greatest attention. Therefore, increasingly, the adoption of sustainable SCM implies integration of OM and human resource management (HRM) practices (de Menezes et al., 2010). Martínez-Jurado and Moyano-Fuentes (2014) stressed that there was a significant gap regarding to social sustainability and sustainable SCM. The key social performance metrics must be identified, a methodology need to be established for their assessment in the sustainable SCM context. An agreement on what the social impacts of a sustainable SCM would be could help to foster research and proper changes in the SCM management in this field, which are urgently needed as illustrated by the horrible situation in the recent Bangladeshi textile factory disaster! There is a giant opportunity to fill this gap by developing a common sphere of knowledge at the interface between the development and honest and ethical implementation of truly sustainable SCM systems, globally.

\subsection{Remanufacturing and networked manufacturing}

Guest editors: Zhang, Yingfeng and Liu, Yang

The rapidly developing and widespread implementation of the information, network, and sustainable technologies and theories in the manufacturing field are resulting increasing demands of agility (Sanchez and Nagi, 2001), networking (Mitsuishi and Nagao, 1999), green, and more effective intelligence in manufacturing (Bi et al., 2014). A variety of advanced manufacturing systems have been developed and implemented to shorten the time to market, to enhance the flexibility and to improve the quality, while reducing costs and alleviating environmental pollution (Xu et al., 2014). Remanufacturing and networked manufacturing are the important examples of such advanced manufacturing systems.

Remanufacturing is an important approach for companies wishing to implement sustainable business plans to achieve long-term success (Goodall et al., 2014). It is designed to provide valueadded through remanufacturing of products to 'as good-as-new' quality (Tian et al., 2014). Other approaches for improved management include waste prevention/avoidance, material's recovery, and other closed-loop systems designed to help to achieve more environmentally and economically sustainable societal systems (Guide et al., 1999). 
Networked manufacturing (NM) means that manufacturing enterprises carry out product design, manufacturing, sales, procurement, management and a series of activities based on network technology especially the Internet. It provides the environment and implementation methods for enterprises to develop remote, collaborative design and manufacturing, online marketing, supply chain management, through the information sharing between/among firms of a manufacturing network. It also helps to ensure business process integration, and resource sharing among enterprises of different locations (D'Amours et al., 1999; Yan, 2000). It builds upon the resources of enterprise groups, including visions, policies, management, design, manufacturing, and marketing resources, to improve their integrated competency (Iwamura et al., 2006).

Therefore, the new strategies and methodologies of remanufacturing and networked manufacturing are playing increasingly important roles in improving productivity, enhancing safety, reducing energy consumption, and reducing negative environmental and human health impacts. For example, emerging real-time manufacturing management frameworks such as the Internet of Manufacturing Things (Zhang et al., 2015b), and cloud manufacturing ( $\mathrm{He}$ and $\mathrm{Xu}, 2014$ ) can promote dynamic optimization to enhance productivity based on real-time data.

Within this context, authors were invited to submit papers about innovative strategies, methodologies and models for remanufacturing and for networked manufacturing management. Topics of interest included but were not limited to:

- Innovative production scheduling strategies and models for remanufacturing and networked manufacturing

- Real-time decision-making strategies and models for remanufacturing and networked manufacturing

- Manufacturing resource configuration methods that are designed to catalyse the transition to equitable, post-fossil carbon societies

\subsubsection{In this theme}

There are two papers in this theme, which addressed social aspects of sustainable manufacturing.

The paper by Dubey, Gunasekaran, Helo, Papadopoulos, Childe, and Sahay in Volume 141, Pages 56-66 developed a theoretical model that linked reconfigurable manufacturing systems with top management beliefs, participation, and environmental performance by building upon agency theory and organizational culture. The authors considered the possible confounding effects of organizational size and organizational compatibility. By drawing on responses from 167 top managers, the results of hypothesis testing suggested that (i) higher top management participation, was influenced by top management's beliefs, which resulted in higher probabilities of RMS becoming adopted by organizations as their manufacturing strategy; (ii) organizational culture moderated the relationships between the level of top management participation and RMS (and manufacturing strategies) adoption; and (iii) higher re-configurability of manufacturing systems led to better environmental performance. Furthermore, the authors of this paper integrated Agency 
Theory and organizational culture to explain the roles of top management's beliefs and participation in achieving environmental performance via RMS. Additionally, the authors provided guidance to managers who would like to engage in leveraging top management commitment for achieving improved environmental performance.

The paper by Salido, Escamilla, Barber, and Giret in this issue focused on recovery in dynamic job-shop scheduling problems where machines could work at different rates under the demands for profitable and sustainable industrial processes. In their study, machine speed scaling was an alternative framework to the on/off control framework for production scheduling. Thus, given a disruption, the main goal was to recover the original solution by rescheduling the minimum number of tasks. To this end, a new match-up technique and a memetic algorithm were developed to determine the rescheduling zone and a feasible reschedule, and find a schedule that minimized the energy consumption within the rescheduling zone but that also met the makespan constraints, respectively. An extensive study was performed to analyse the behaviour of their algorithms to recover the original solution and to minimize the energy consumption in different benchmarks from the OR-Library. Upon a disruption, different rescheduling solutions could be obtained, all of which complied with the requirements but that had different values of energy consumption. Their study should be useful for application in real industries for improved energy efficiency production rescheduling.

\subsubsection{Current reality}

Recently, advanced technologies and management methods were applied to optimize production procedures for remanufacturing and networked manufacturing (Ferrer et al., 2011).

Radio frequency identification (RFID) has been widely used in supporting the production and scheduling management in manufacturing shop floor where manufacturing resources attached with RFID facilities were converted into smart manufacturing objects, capable of sensing, and interacting, to create an Internet of Manufacturing Things (IoMT) environment.

Under the real-time information capturing and integration framework of IoMT, the real-time information of manufacturing resources can be sensed and captured (Zhang et al., 2015a). Additionally, the multi-objective scheduling optimization method for improved real-time production scheduling is an essential element for achieving improved sustainable competitive advantages for the enterprises. Because remanufacturing and networked manufacturing often linked to sustainability (Mayyas et al., 2012), the three pillars of sustainability, namely, economic, environmental and social, are often used to categorize the unique decision-making factors when assessing the optimization results of remanufacturing. A multi-agent based real-time production scheduling method was provided for a RFID enabled, ubiquitous shop floor environment (Zhang et al., 2014). A decision-making architecture to determine maintenance and production scheduling policies based on the condition-monitoring information was developed and implemented to 
significantly improve the system performance about expected average profits and total maintenance costs (Lee and $\mathrm{Ni}, 2013$ ).

\subsubsection{Future potential and challenges}

With the rapid developments of the Internet of Things (IoT), product service systems and big data technologies, much progress has been made in applying the advanced technologies of remanufacturing and networked manufacturing in the industrial field. However, there are more problems, which must be solved.

Firstly, there is a lack of systematic solutions of automatic identification and capturing for lifecycle data of the products, thus the data acquisition during manufacturing and maintenance is inaccurate and incomplete, the complexity in planning, execution, and control of remanufacturing operation may be increased, and ultimately it may negatively affect energy efficiency improvements of remanufacturing processes (Zhang et al., 2016c).

Secondly, production scheduling issues on remanufacturing shop floors are more complex than that in manufacturing shop floor, and they require significant modifications compared to traditional production scheduling. This results in situations where the effects of that on cost, energy consumption, and worker load is a vital restriction factor to implement universal production remanufacturing. Therefore, how to structure a real-time data-driven optimization method for production scheduling based on the real-time information of manufacturing resources is the key to achieve efficient control over remanufacturing process and multi-objective optimization of production scheduling.

Thirdly, by extending the IoT and cyber-physical system (CPS) technologies to the manufacturing field, real-time and multi-source data have become more accessible and ubiquitous, which creates the big data environment. The large amounts of real-time data from the sensor network will challenge the traditional manner of material handling systems, which provides an opportunity to improve the shop floor transport efficiency (Zhang et al., 2016b).

Fourthly, modern logistical systems are making significant progress and rapid developments with the prosperity of E-commerce. Typical challenges that the logistics systems management is facing are due to: (1) a lack of sharing; (2) a lack of standards; (3) a lack of an integrated cost effective environmental package; (4) a lack of an efficient optimization method for logistical distribution tasks. Thus, it is difficult to implement green, sustainable logistical services (Zhang et al., 2016a). We also call for future research to give suggestions for how to 'solve' these problems.

\subsection{Knowledge management for sustainable societal development}

Guest editors: Naaranoja, Marja and Kantola, Jussi 
Knowledge is the key factor to achieve goals, such as sustainable societal development. According to Daveport and Prusak (2000), sustainable advances for a company is gained from its collective knowledge base, efficient use of the knowledge base, and quick acquisition and application of new knowledge. The same is true for organizations and societies. A single firm or organization can manage its intellectual assets easier than a society can. A company has strategy but society is a collection with many strategies by many companies and organizations. For a society, it is more difficult to achieve its goals than for a single company or organization to do so. Sustainable societal development is advancement that requires systemic co-operation in terms of company and organizational knowledge, they should build upon their strengths to innovate the planning, development, production of products and provision of services in an integrated and systematic manner. The essence of cooperation behind sustainable societal development is to provide equitable access to knowledge; to support transferring and sharing of knowledge; and to catalyse usage of knowledge (c.f. Nonaka and Takeuchi, 1995).

In this context, Knowledge Management (KM) is a broad and multi-disciplinary concept that can be defined from different perspectives. For example, KM is "the process of capturing, developing, sharing, and effectively using organizational knowledge" (Davenport, 1994); or the purpose of $\mathrm{KM}$ is "to maximize the enterprise's knowledge-related effectiveness and returns from its knowledge assets and to renew them constantly" (Wiig 1997). Simply, KM is 1) collected and generated; 2) transferred and shared; and 3) stored and used.

Another interpretation of KM in the context of sustainable societal development is: $\mathrm{KM}$ is a collaborative approach to create, capture, organize, access, and use society's intellectual assets to innovate products and services for sustainable societal development.

Knowledge managers' role is to design ways to do this in practice so that knowledge bases can be collaboratively renewed. Support for breakthrough ideas, their testing, publicizing and implementation is important. Equally important are documentation of lessons learned, and building of institutional and inter-institutional memory to support corporate and societal systems in sustainable pathways for the short and long-term future.

Knowledge architecture refers to strategy and activities together (Akhavan et al., 2006). KM covers all primary activities (inbound logistics, operations, sales and marketing, service and outbound logistics) as well as support activities in firms' and organizations' value chain (Porter 1985). It can be understood so that the knowledge strategy and architecture can be designed so that the company's primary and support activities create value in parallel with creating innovative products and services for sustainable societal development.

\subsubsection{In this theme}

There is one article in this theme: Study of business models for sustainable innovation by Rosca, E. Arnold, M.G. and Bendul, in this issue. 
Rosca et al. studied how can frugal and reverse innovations strengthen a company's contributions to sustainable societal development, and how can relevant sustainable business approaches be systemized and described? Their case study covered tens of frugal products and services from a business models and sustainability strategy perspective from June 2014 until June 2015. The authors' results show that companies offering frugal and reverse products and services apply business models in an insightful manner to create economic, social and environmental value.

\subsubsection{Current reality}

By definition, $\mathrm{KM}$ is the process of capturing, distributing, and effectively using knowledge (Davenport, 1994). Capturing, identifying and creating knowledge describe activities that take place upstream in a KM system from customers' perspective. Storing, distributing and sharing describe activities in the mid parts of KM system. Using, applying and disseminating describe activities in downstream of a KM system. For feedback loops from customers to producers the logic is the opposite. Companies and organizations can use KM systems for these activities and KM strategies to guide their activities. These are all active areas of research and practice today. There is not much literature available on how KM can support societal sustainable development.

\subsubsection{Future potential and challenges}

In the area of KM, there is need to provide support to develop, test and implement sustainable solutions, since it can easily cross boundaries over disciplines and therefore, can support activities to achieve holistic approaches. There are effective KM methods, tools and systems available today for companies but there are fewer support tools for humans and for non-business organisations.

But is there the will and openness to work together? In answer to that question, companies often protect their knowledge and may not easily provide it for broader societal usage and co-operation. KM can support innovation management and product and service development, which can be organized differently from the way it is today. Some companies already provide some of their knowledge assets for co-development and value co-creation. New cross-boundary processes can be innovated to remove boundaries from value adding flows to develop products and services. KM is already equipped to do this. All we need is the will and commitment to co-evolve together. Sustainable societal development surely is a win-win situation for all parties if they work together!

In KM managing content in this context is becoming the key to holistic understanding of complex situations and for projecting possible alternative future scenarios (Kantola 2015). It is important to know which ontologies of complex objects exist, how they can be accessed and applied. Also, organizational resources, such as intellectual assets and competences are such complex objects that they require ontological modelling.

KM can support the leveraging of knowledge to society's advantage, i.e. sustainable societal development in this case. Societal intellectual assets could be more effectively built upon to help 
to produce societal success via usage of well-designed KM systems. This can be done by implementing KM methods and processes for individuals, groups and communities in the society. KM for sustainable societal development should support value management that serves in decision-support functions for selecting which principles or guidelines should be followed. Vision, mission and values can be co-developed by stakeholders as well as uniformly communicated and implemented as an integral part of sustainable societal organizational planning and operation.

Recent review studies have explored what sustainable innovations are made of (de Medeiros et al., 2014). Such frameworks can be helpful for innovators. In addition, a responsive environment (Ford, 1992; Tannebaum, 1997) for innovators and sustainable societal development is needed. For that, strategic management of corporations (Engert et al., 2016) as well as governmental decision-making and policy-making support are required (Droste et al., 2016). Support from the top is necessary for advancement.

\section{Acknowledgements}

We would like to acknowledge the International Conference on Innovation and Management (ICIM) partner universities (Tilburg University, Wuhan University of Technology, Universiti Teknologi Malaysia, PUC-São Paulo University, Yamaguchi University and University of Vaasa) as well as the ICIM2014 organizing team at the University of Vaasa. The ICIM2014 held at University of Vaasa in November 2014 initiated the idea for this SV. We would like to thank Elsevier and Dr. Donald Huisingh and Dr. Rodrigo Lozano for the opportunity and guidance in preparing this SV. The effort by all the reviewers who involved in this SV is highly appreciated. Also, we would like to thank all the authors of this SV for their contributions.

\section{References}

Agrawal, V. V., Ülkü, S., 2013. The Role of Modular Upgradability as a Green Design Strategy. Manuf. Serv. Oper. Manag. 15, 640-648. doi:10.1287/msom.1120.0396

Ahuja, G., 2000. Collaboration Networks, Structural Holes, and Innovation: A Longitudinal Study. Admin. Sci. Quart., 45(3), 425-455.

Akhavan, P., Jafari, M. Mohammad F., 2006. Critical Success Factors of Knowledge Management Systems: a Multi-Case Analysis. Eur. Bus. Rev. J., 18 (2), 97-113.

Andersen, M., Skjoett-Larsen, T., 2009. Corporate social responsibility in global supply chains. Supply Chain Manag. An Int. J. 14, 75-86. doi:10.1108/13598540910941948

Beckman, C. M., Haunschild, P. R., Phillips, D. J., 2004. Friends or Strangers? Firm-specific Uncertainty, Market Uncertainty, and Network Partner Selection. Organ. Sci., 15 (3), 259-275. 
Belderbos, R., Carree, M., Lokshin, B., 2004. Co-operative R\&D and Firm Performance. Res. Policy., 33 (10), 1477-1492.

Bendul, J.C., Rosca, E., Pivovarova, D., 2016. Sustainable supply chain models for base of the pyramid. J. Clean. Prod. doi:10.1016/j.jclepro.2016.11.001 (in this issue)

Beske, P., Koplin, J., Seuring, S., 2008. The use of environmental and social standards by German first-tier suppliers of the Volkswagen AG. Corp. Soc. Responsib. Environ. Manag. 15, 63-75. doi: $10.1002 /$ csr. 136

Bi, Z., Xu, L. Da, Wang, C., 2014. Internet of things for enterprise systems of modern manufacturing. IEEE Trans. Ind. Informatics 10, 1537-1546. doi:10.1109/TII.2014.2300338

Burt, R. S., 2005. Brokerage and Closure: An Introduction to Social Capital. Oxford, England: Oxford University Press.

Carvalho, H., Duarte, S., Cruz Machado, V., 2011. Lean, agile, resilient and green: divergencies and synergies. Int. J. Lean Six Sigma 2, 151-179.

Chesbrough, H., 2003. Open innovation. Cambridge, England: Harvard University Press.

Comm, C.L., Mathaisel, D.F.X., 2008. Sustaining higher education using Wal-Mart's best supply chain management practices. Int. J. Sustain. High. Educ. 9, 183-189. doi:10.1108/14676370810856323

Corbett, C.J., Klassen, R.D., 2006. Extending the horizons: environmental excellence as key to improving operations. Manuf. Serv. Oper. Manag. 8, 5-22.

D’Amours, S., Montreuil, B., Lefrançois, P., Soumis, S., 1999. Networked manufacturing: The impact of information sharing. Int. J. Prod. Econ., 58, 63-79.

Das, T. K., Teng, B. S., 1996. Risk Types and Inter-firm Alliance Structures. J. Manage. Stud., 33(6), 827-843.

Das, T. K., Teng, B. S., 1998. Between Trust and Control: Developing Confidence in Partner Cooperation in Alliances. Acad. Manage. Rev., 23(3), 491-512.

Davenport, T., 1994. Saving IT's Soul: Human Centered Information Management. Harvard Bus. Rev., 72 (2), 119-131.

Davenport, T., Prusak, L., 2000. Working knowledge: How Organizations Manage What They Know. Harvard Business Review Press; 2nd edition, 240 p.

Deeds, D. L., Rothaermel, F. T., 2003. Honeymoons and Liabilities: The Relationship Between Age and Performance in Research and Development Alliances. J. Prod. Innovat .Manag., 20(6), 468-484. 
De Leeuw, T. and Gössling, T., 2016. Theorizing Change Revisited: An Amended Process Model of Institutional Innovations and Changes in Institutional Fields, J. Clean. Prod., 135, 435448.

De Leeuw T, Lokshin B, Duysters G., 2014. Returns to Alliance Portfolio Diversity: The Relative Effects of Partner Diversity on Firm's Innovative Performance and Productivity. J, Bus. Res. 9(67), 1839-1849.

De Man, A., Duysters, G., 2005. Collaboration and Innovation: A Review of the Effects of Mergers, Acquisitions and Alliances on Innovation. Technovation, 25, 1377-1387.

De Man, A., Duysters, G., Krijnen, A., Luvison, D., 2011. State of Alliance Management Study 2011. For the Association of Strategic Alliance Professionals.

De Medeiros, J. F., Duarte Ribeiro, J. L., Nogueira Cortimiglia, M., 2014. Success factors for environmental sustainable product innovation: a systematic literature review. J. Clean. Prod., 65, 76-86.

De Menezes, L.M., Wood, S., Gelade, G., 2010. The integration of human resource and operation management practices and its link with performance: A longitudinal latent class study. J. Oper. Manag. 28, 455-471.

Drake, D.F., Kleindorfer, P.R., Van Wassenhove, L.N., 2015. Technology choice and capacity portfolios under emissions regulation. Prod. Oper. Manag.

Drake, D.F., Spinler, S., 2013. Sustainable Operations Management: An Enduring Stream or a Passing Fancy? Manuf. Serv. Oper. Manag. 15, 689-700. doi:10.1287/msom.2013.0456

Droste, N., Hansjürgens, B., Kuikman, P., Otter, N., Antikainen, R., Leskinen, P., Pitkänen, L., Saikku, E., Thomsen, M., (2016). Steering innovations towards a green economy: Understanding government intervention. J. Clean. Prod., 135, 426-434.

Dubey, R., Gunasekaran, A., Helo, P., Papadopoulos, T., Childe, S.J., Sahay, B.S., 2017. Explaining the impact of reconfigurable manufacturing systems on environmental performance: The role of top management and organizational culture. J. Clean. Prod. 141, 56-66. doi:10.1016/j.jclepro.2016.09.035

Dües, C.M., Tan, K.H., Lim, M., 2013. Green as the new Lean: How to use Lean practices as a catalyst to greening your supply chain. J. Clean. Prod. 40, 93-100. doi:10.1016/j.jclepro.2011.12.023

Elkington, J., 1998. Cannibals with Forks: The Triple Bottom Line of 21st Century Business, Conscientious Commerce. doi:0865713928 
Engert, S., Rauter, R., Baumgartner, R.J., 2016. Exploring the integration of corporate sustainability into strategic management: A literature review. J. Clean. Prod., 112, 2833-28.

Ferrer, G., Heath, S.K., Dew, N., 2011. An RFID application in large job shop remanufacturing operations. Int. J. Prod. Econ. 133, 612-621. doi:10.1016/j.ijpe.2011.05.006

Ford, M. E., 1992. Motivating humans: Goals, emotions, and personal agency beliefs. Sage Publications.

Goodall, P., Rosamond, E., Harding, J., 2014. A review of the state of the art in tools and techniques used to evaluate remanufacturing feasibility. J. Clean. Prod. 81, 1-15. doi:10.1016/j.jclepro.2014.06.014

Govindan, K., Khodaverdi, R., Jafarian, A., 2013. A fuzzy multi criteria approach for measuring sustainability performance of a supplier based on triple bottom line approach. J. Clean. Prod. 47, 345-354. doi:10.1016/j.jclepro.2012.04.014

Guide, V.D.R., Jayaraman, V., Srivastava, R., 1999. Production planning and control for remanufacturing: a state-of-the-art survey. Robot. Comput. Integr. Manuf. 15, 221-230. doi:10.1016/S0736-5845(99)00020-4

Hagedoorn, J., 1993. Understanding the Rationale of Strategic Technology Partnering: Interorganizational Modes of Cooperation and Sectoral Differences. Strategic. Manage. J., 14(5), $371-385$.

He, W., Xu, L., 2014. A state-of-the-art survey of cloud manufacturing. Int. J. Comput. Integr. Manuf. 28, 239-250. doi:10.1080/0951192X.2013.874595

Hyysalo, S., Johnson, M., Juntunen, J.K., 2016. The diffusion of consumer innovation in sustainable energy technologies. J. Clean. Prod. doi:10.1016/j.jclepro.2016.09.045 (in this issue)

Islegen, O., Reichelstein, S., 2011. Carbon Capture by Fossil Fuel Power Plants: An Economic Analysis. Manage. Sci. 57, 21-39. doi:10.1287/mnsc.1100.1268

Iwamura, K., Okubo, N., Tanimizu, Y., Sugimura, N., 2006. Real-time scheduling for holonic manufacturing systems based on estimation of future status. Int. J. Prod. Res. 44, 3657-3675. doi:10.1080/00207540600847129

Kantola, J., 2015. Organizational Resource Management - Theories, Methodologies and Applications. CRC Press.

Kantola, J., Liu, Y., Zhang, Y., Segev, A., De Leeuw, T., Naaranoja, M., Peura, P., 2015. Call for papers for a special volume of the Journal of Cleaner Production on "Innovative products and services for sustainable societal development”. J. Clean. Prod., 93, 1-4. 
Keil, T., Maula, M., Schildt, H., Zahra, S. A., 2008. The Effect of Governance Modes and Relatedness of External Business Development Activities on Innovative Performance. Strategic. Manage. J.29(8), 895-907.

Kieckhaefer, K., Wachter, K. and Spengler, T.S., 2016. Analyzing manufacturers' impact on green products' market diffusion - the case of electric vehicles, J. Clean. Prod. (in this issue)

Lee, S., Ni, J., 2013. Joint decision making for maintenance and production scheduling of production systems. Int. J. Adv. Manuf. Technol. 66, 1135-1146. doi:10.1007/s00170-012-43956

Levine, S., White, P. E., 1961. Exchange as a conceptual framework for the study of interorganizational relationships. Admin. Sci. Quart. 5(4), 583-601.

Liu, Y., 2013. Sustainable competitive advantage in turbulent business environments. Int. J. Prod. Res. 51, 2821-2841. doi:10.1080/00207543.2012.720392

Liu, Y., Liang, L., 2015. Evaluating and developing resource-based operations strategy for competitive advantage: an exploratory study of Finnish high-tech manufacturing industries. Int. J. Prod. Res. 53, 1019-1037. doi:10.1080/00207543.2014.932936

Marti, C.P., 2016. Sustainable energy systems and company performance: Does the implementation of sustainable energy systems improve companies' financial performance?, J. Clean. Prod. (in this issue)

Martínez-Jurado, P.J., Moyano-Fuentes, J., 2014. Lean management, supply chain management and sustainability: A literature review. J. Clean. Prod. 85, 134-150. doi:10.1016/j.jclepro.2013.09.042

Matinheikki, J., Rajala, R., Peltokorpi, A., 2016. From the profit of one toward benefitting many - Crafting a vision of shared value creation. J. Clean. Prod. doi:10.1016/j.jclepro.2016.09.081 (in this issue)

Mayyas, A., Qattawi, A., Omar, M., Shan, D., 2012. Design for sustainability in automotive industry: A comprehensive review. Renew. Sustain. Energy Rev. doi:10.1016/j.rser.2012.01.012

McDonald, S., Young, S., 2012. Cross-sector collaboration shaping Corporate Social Responsibility best practice within the mining industry. J. Clean. Prod., 37, 54-67.

Metters, R., 1997. Quantifying the Bullwhip Effect in Supply Chains. J. Oper. Manag., 15(2), 89100.

Mitsuishi, M., Nagao, T., 1999. Networked manufacturing with reality sensation for technology transfer. CIRP Ann. Technol. 48, 409-412. 
Mollenkopf, D., Stolze, H., Tate, W.L., Ueltschy, M., 2010. Green, lean, and global supply chains. Int. J. Phys. Distrib. Logist. Manag. 40, 14-41. doi:10.1108/09600031011018028

Mothe, C., Nguyen-Thi, U.T., 2016. Persistent openness and environmental innovation: An empirical analysis of French manufacturing firms. J. Clean. Prod. doi:10.1016/j.jclepro.2016.12.063 (in this issue)

Mowery, D. C., Oxley, J. E., Silverman, B. S., 1996. Strategic Alliances and Interfirm Knowledge Transfer. Strategic. Manage. J., 17, 77-91.

Oliver. C., 1990. Determinants of Interorganizational Relationships: Integration and Future Directions. Acad. Manage. Rev., 15(15), 241-265.

Nonaka, I., Takeuchi, H., 1995. The knowledge creating company: how Japanese companies create the dynamics of innovation. New York: Oxford University Press.

Park, S. H., Russo, M. V., 1996. When Competition Eclipses Cooperation: An Event History Analysis of Joint Venture Failure. Manage. Sci., 42(6), 875-890.

Phuc, N.H. and Matsuura, Y., 2016. Designing a sustainability framework for the initiation and management of coordination in an energy exchange, J. Clean. Prod. (in this issue)

Plambeck, E., Wang, Q., 2009. Effects of E-Waste Regulation on New Product Introduction. Manage. Sci. 55, 333-347. doi:10.1287/mnsc.1080.0970

Poot, T., Faems, D., Vanhaverbeke, W., 2009. Toward a Dynamic Perspective on Open Innovation: A Longitudinal Assessment of the Adoption of Internal and External Innovation Strategies in the Netherlands. Int. J. Innovation. Man., 13(2), 177-200.

Porter, M. E., 1985. The Competitive Advantage: Creating and Sustaining Superior Performance. NY: Free Press.

Purtik, H., Zimmerling, E. and Welpe, I.M., 2016. End-Users as Co-Developers for Novel Green Products and Services - An Exploratory Case Study Analysis of the Innovation Process in Incumbent Firms, J. Clean. Prod. (in this issue)

Provan, K. G., Fish, A., Sydow, J., 2007. Interorganizational Networks at the Network Level: A Review of the Empirical Literature on Whole Networks. J. Manage., 33(3), 479-516.

Raz, G., Druehl, C.T., Blass, V., 2013. Design for the environment: Life-cycle approach using a newsvendor model. Prod. Oper. Manag. 22, 940-957. doi:10.1111/poms.12011

Rosca, E. Arnold, M.G. and Bendul, J. 2016. Business models for sustainable innovation - an empirical analysis of frugal products and services, J. Clean. Prod. (in this issue) 
Rosenzweig, E. D., Roth, A. V., Dean, J. W., 2003. The Influence of an Integration Strategy on Competitive Capabilities and Business Performance: An Exploratory Study of Consumer Products Manufacturers. J. Oper. Manag., 21(4), 437-456.

Sabidussi A, Lokshin B, De Leeuw T, Duysters G, Bremmers H, Omta O., 2014. A Comparative Perspective on External Technology Sourcing Modalities: The Role of Synergies. J. Eng. Technol. Manage. (33), 18-31.

Salido, M.A., Escamilla, J., Barber, F., Giret, A., 2016. Rescheduling in job-shop problems for sustainable manufacturing systems. J. Clean. Prod. doi:10.1016/j.jclepro.2016.11.002 (in this issue)

Sanchez, L., Nagi, R., 2001. A review of agile manufacturing systems. Int. J. Prod. Res. 39, 35613600. doi:10.1080/00207540110068790

Seuring, S., Muller, M., 2008. From a literature review to a conceptual framework for sustainable supply chain management. J. Clean. Prod. 16, 1699-1710. doi:10.1016/j.jclepro.2008.04.020

Singh, K., Mitchell, W., 1996. Precarious Collaboration: Business Survival After Partners Shut Down or Form New Partnerships. Strategic. Manage. J., 17(1), 99-115.

Smith, D.J., Tranfield, D., 2005. Talented suppliers? Strategic change and innovation in the UK aerospace industry. R\&D Manag. 35, 37-49. doi:10.1111/j.1467-9310.2005.00370.x

Srivastava, M. K., Gnyawali, D. R., 2011. When do Relational Resources Matter? Leveraging Portfolio Technological Resources for Breakthrough Innovation. Acad. Manage. J., 54(4), 797810.

Sun, H., Liu, Y., Sakao, T., Wang, Z., 2016. Configuring use-oriented aero-engine overhaul service with multi-objective optimization for environmental sustainability. J. Clean. Prod. doi:10.1016/j.jclepro.2016.12.022 (in this issue)

Tannenbaum, S. I., 1997. Enhancing continuous learning: Diagnostic findings from multiple companies. Human resource management, 36 (4), 437-452.

Tether, B., 2002. Who Co-operates for Innovation, and Why: An Empirical Analysis. Res. Policy., 31(6), 947-967.

Tian, G., Chu, J., Hu, H., Li, H., 2014. Technology innovation system and its integrated structure for automotive components remanufacturing industry development in China. J. Clean. Prod. 85, 419-432. doi:10.1016/j.jclepro.2014.09.020

Van Hoof, B., Thiell, M., 2014. Collaboration capacity for sustainable supply chain management: Small and medium-sized enterprises in Mexico. J. Clean. Prod. 67, 239-248. doi:10.1016/j.jclepro.2013.12.030 
Von Hippel, E., 2007. Horizontal Innovation Networks - By and For Users. Ind. Corp. Change., 16(2), 293-315.

Wassmer, U., 2010. Alliance Portfolios: A Review and Research Agenda. J. Manage., 36(1), 141171.

Wassmer, U., Dussauge, P. 2011. Value Creation in Alliance Portfolios: The Benefits and Costs of Network Resource Interdependencies. Eur. Manag. Rev., 8(1), 47-64.

Wassmer, U., Dussauge, P. 2012. Network Resource Stocks and Flows: How do Alliance Portfolios Affect the Value of new Alliance Formations? Strategic. Manage. J., 33(7), 871-883.

Wee, H.M., Wu, S., 2009. Lean supply chain and its effect on product cost and quality: a case study on Ford Motor Company. Supply Chain Manag. An Int. J. 14, 335-341. doi:10.1108/13598540910980242

Wiig, K. M., 1997. Integrating intellectual capital and knowledge management. Long. Range. Plann., 30 (3), 399-405.

Wolf, J., 2011. Sustainable Supply Chain Management Integration: A Qualitative Analysis of the German Manufacturing Industry. J. Bus. Ethics 102, 221-235. doi:10.1007/s10551-011-0806-0

Wu, K.J., Liao, C.J., Tseng, M.L., Lim, M.K., Hu, J., Tan, K., 2015. Toward sustainability: Using big data to explore the decisive attributes of supply chain risks and uncertainties. J. Clean. Prod. doi:10.1016/j.jclepro.2016.04.040

$\mathrm{Xu}, \mathrm{L} . \mathrm{Da}, \mathrm{He}, \mathrm{W} ., \mathrm{Li}, \mathrm{S} ., 2014$. Internet of things in industries: A survey. IEEE Trans. Ind. Informatics. doi:10.1109/TII.2014.2300753

Yan, J.Q., 2000. Digitized, network-based manufacturing. Ind. Eng. Manag. 1, 8-11.

Zhang, Y., Huang, G., Sun, S., Yang, T., 2014. Multi-agent based real-time production scheduling method for radio frequency identification enabled ubiquitous shop floor environment. Comput. Ind. Eng. 76, 89-97. doi:10.1016/j.cie.2014.07.011

Zhang, Y., Liu, S., Liu, Y., Li, R., 2016a. Smart box-enabled product-service system for cloud logistics. Int. J. Prod. Res. 54(22), 6693-6706.

Zhang, Y., Qian, C., Lv, J., Liu, Y. 2016b. Agent and cyber-physical system based self-organizing and self-adaptive intelligent shop floor. IEEE Trans. Ind. Informatics. 1-11. DOI:10.1109/TII.2016.2618892.

Zhang, Y., Ren, S., Liu, Y., Si, S., 2016c. A big data analytics architecture for cleaner manufacturing and maintenance processes of complex products. J. Clean. Prod. doi:10.1016/j.jclepro.2016.07.123 
Zhang, Y., Zhang, G., Du, W., Wang, J., Ali, E., Sun, S., 2015a. An optimization method for shop floor material handling based on real-time and multi-source manufacturing data. Int. J. Prod. Econ. $165,282-292$.

Zhang, Y., Zhang, G., Wang, J., Sun, S., Si, S., Yang, T., 2015b. Real-time information capturing and integration framework of the internet of manufacturing things. Int. J. Comput. Integr. Manuf. 28 (8), 811-822. doi:10.1080/0951192X.2014.900874 